\title{
Increased Secretion of Atrial Natriuretic Polypeptide from the Left Ventricle in Patients with Dilated Cardiomyopathy
}

\author{
Hirofumi Yasue, Kenji Obata, Ken Okumura, Mitsuro Kurose, Hisao Ogawa, Koshi Matsuyama, Michihisa Jougasaki, \\ Yoshihiko Saito," Kazuwa Nakao, * and Hiroo Imura* \\ Division of Cardiology, Kumamoto University Medical School, Kumamoto 860; and *Second Division, Department of Medicine, \\ Kyoto University School of Medicine, Kyoto 606, Japan
}

\begin{abstract}
To examine whether atrial natriuretic polypeptide (ANP) is released from the left ventricle in patients with dilated cardiomyopathy (DCM) we measured plasma ANP level in the aortic root (Ao), the anterior interventricular vein (AIV), the great cardiac vein (GCV), and the coronary sinus (CS) in 11 patients with DCM and 18 control subjects. Plasma ANP levels in Ao, $A I V, G C V$, and CS were $454 \pm 360,915 \pm 584,1,308 \pm 926$, and $1,884 \pm 1,194 \mathrm{pg} / \mathrm{ml}$, respectively, in the patients with DCM and $108 \pm 42,127 \pm 55,461 \pm 224$, and $682 \pm 341 \mathrm{pg} / \mathrm{ml}$, respectively, in the control subjects. There was no significant difference in the plasma ANP levels between Ao and AIV in the control subjects. On the contrary, there was a significant $(P$ $<0.001$ ) step-up in plasma ANP levels between Ao and AIV in patients with DCM. Thus, the difference in ANP levels between Ao and AIV was significantly increased in patients with DCM as compared with the control subjects (461 \pm 248 vs. $19 \pm 59 \mathrm{pg} / \mathrm{ml}, P<0.001)$. The difference in ANP levels between Ao and CS was also significantly increased in patients with DCM as compared with the control subjects $(1,429 \pm 890$ vs. $577 \pm 318 \mathrm{pg} / \mathrm{ml}, P<0.001)$. We conclude that ANP is released in increased amounts into the circulation from the left ventricle as well as from the heart as a whole in patients with DCM.
\end{abstract}

\section{Introduction}

Atrial natriuretic polypeptide (ANP) ${ }^{1}$ is a circulating hormone with a wide range of potent biological effects, including natriuresis, diuresis, vasodilatation, and inhibition of renin and aldosterone secretion (1-5), and there is now increasing evidence that it plays an important role in the regulation of fluid volume and blood pressure (2-5). Studies using RIA have indicated that plasma ANP levels are increased in patients with congestive heart failure (6-10) and that there is a linear rela-

Address correspondence to Dr. Hirofumi Yasue, Division of Cardiology, Kumamoto University Medical School, 1-1-1, Honjou, Kumamoto City, Kumamoto 860 , Japan.

Received for publication 8 March 1988 and in revised form 29 June 1988.

1. Abbreviations used in this paper: AIV, anterior interventricular vein; ANP, atrial natriuretic polypeptide; Ao, aortic root; CS, coronary sinus; DCM, dilated cardiomyopathy; GCV, great cardiac vein; hANP, human ANP.

J. Clin. Invest.

(c) The American Society for Clinical Investigation, Inc.

0021-9738/89/01/0046/06 \$2.00

Volume 83, January 1989, 46-51 tion between plasma ANP level and atrial pressure $(9,10)$, implying that atrial pressure or stretch plays an important role in regulating secretion of ANP.

Since the pioneering observation of de Bold and his coworkers (11) ANP has been thought to be present in the atria but not in the ventricles of adult mammals $(1-5,12)$. However, several recent reports have demonstrated that the ventricle is capable of synthesizing and storing substantial amounts of ANP during cardiac hypertrophy and failure in rats and hamsters (13-17). We have reported a patient with dilated cardiomyopathy (DCM) who died of congestive heart failure; the patient showed very high levels of plasma ANP and increased tissue levels of both ANP and ANP mRNA in the left ventricle at autopsy (18). Recently Edwards and his co-workers demonstrated immunohistochemically the presence of ANP within human ventricles with congestive heart failure (19). However, it is not known either in animals or in humans whether ANP is actually released from the left ventricle into the circulation. We have shown that ANP is released into the general circulation at least partially by way of the coronary sinus (CS; 6, 20). Because the CS receives blood from both the atria and the ventricles, and because the anterior interventricular vein (AIV) which empties into the coronary sinus by way of the great cardiac vein (GCV) is thought to drain the left ventricle and not the atria (21-23), the difference of plasma ANP levels between the AIV and the aortic root (Ao) is thought to reflect the amount of ANP released from the left ventricles and not the atria.

The present study was designed to examine whether ANP is released in increased amounts from the left ventricle in patients with DCM as compared with the control subjects by sampling blood for ANP from the Ao and various sites in the CS system including the AIV.

\section{Methods}

Patients. 11 patients ( 10 men and 1 woman, ages ranging from 49 to 71 $\mathrm{yr}$, with a mean age of $60 \mathrm{yr}$ ) with DCM in whom diagnostic cardiac catheterizations were performed and in whom insertion of catheters into the AIV was possible were the subjects of this study. The diagnosis of DCM was based on history, physical examination, chest x-ray, electrocardiogram, echocardiogram, cardiac catheterization, and angiocardiography, including left ventriculography and coronary arteriography. Endomyocardial biopsy was also done in seven of the patients. In all patients ischemic heart disease, hypertension, valvular heart disease, congenital malformation of heart and vessels, or intrinsic pulmonary parenchymal or vascular disease were excluded. The patients were receiving diuretics and a combination of digitalis $(n=6)$, calcium antagonists $(n=3)$, or nitrates $(n=4)$, although treatment was withheld on the day before the study. We selected as control subjects 18 patients without heart muscle diseases and heart failure (12 men and 6 women, ages ranging from 21 to 71 , with a mean age of 53) in whom diagnostic cardiac catheterizations were performed and in whom in- 
Table I. Catheterization data

\begin{tabular}{lccccccc}
\hline & HR & AOP & RAP & PCWP & CI & EF & ESVI \\
\hline & beats $/$ min & & $m m H g$ & & liters $/ \mathrm{min} / \mathrm{m}^{2}$ & $\%$ & $\mathrm{ml} / \mathrm{m}^{2}$ \\
Control & $72 \pm 11$ & $92 \pm 16$ & $4 \pm 2$ & $7 \pm 2$ & $3.1 \pm 0.5$ & $69 \pm 8$ & $22 \pm 9$ \\
DCM & $74 \pm 14$ & $102 \pm 17$ & $6 \pm 4$ & $13 \pm 10$ & $2.3 \pm 0.6$ & $31 \pm 9$ & $69 \pm 14$ \\
$P$ & NS & NS & NS & $<0.05$ & $<0.001$ & $<0.001$ & $<0.001$
\end{tabular}

AOP, mean aortic pressure; $\mathrm{CI}$, cardiac index; EF, ejection fraction; ESVI, endsystolic volume index; HR, heart rate; NS, not significant; PCWP, pulmonary capillary wedge pressure; RAP, right atrial pressure.

sertion of catheters into the AIV was possible. They consisted of nine patients with chest pain syndrome with normal coronary arteriograms, five patients with angina pectoris without previous myocardial infarction, and four patients with electrocardiographic abnormalities. None of them had myocardial infarction, hypertension, cardiac hypertrophy, or other heart muscle diseases. None of them was receiving therapy at the time of the study except two patients with angina pectoris who were on nitrates.

Written informed consent was obtained from each patient.

Cardiac catheterization. Cardiac catheterization was performed in the morning in the fasting state. After the right heart catheterization was done using a Swan-Ganz catheter placed in the main pulmonary artery, a 6-French Goodale-Lubin catheter was placed in the CS by way of a brachial vein. The catheter was then advanced to the AIV under fluoroscopy using a guide wire. The position of the catheter tip in the AIV was confirmed by injection of contrast dye. This was the critical part of the study and the patients in whom at least the proximal half of the AIV was not visualized were excluded from the study. A Sones catheter was placed at the root of the aorta by way of a brachial artery. Sampling of blood for ANP was done simultaneously at the root of the aorta, the AIV, the GCV, and the CS. Care was taken to draw blood samples slowly from the AIV. Data from the initial part of the study that included samples drawn forcibly were discarded because we found that forcible drawing of blood from the AIV resulted in spuriously high levels of plasma ANP, probably because backflow from the GCV occurred and contaminated the AIV with higher concentrations of ANP.

$R I A$ for $A N P$. All blood samples were withdrawn into chilled plastic syringes and transferred to chilled siliconized disposable tubes that contained aprotinin (1,000 kallikrein inactivator units/ml) (Ohkura Pharmaceutical, Kyoto, Japan) and EDTA $(1 \mathrm{mg} / \mathrm{ml})$, then immediately placed on ice and centrifuged at $4^{\circ} \mathrm{C}$. An aliquot of plasma was immediately frozen at $-20^{\circ} \mathrm{C}$ and thawed only once at the time of extraction. Plasma ANP concentration was measured by the RIA for ANP as previously reported (6). Antibodies were raised in New Zealand white rabbits immunized with synthetic alpha human ANP (hANP). This RIA recognizes a common carboxy-terminal sequence of alpha hANP and is equally specific for both alpha hANP and alpha rat ANP. Cross-reactivities with beta hANP and gamma hANP in the RIA are 120 and $100 \%$ on a molar basis. No cross-reactions were observed with renin, angiotensin II, aldosterone, digoxin, nitrates, calcium antagonists, or diuretic agents. The minimal detectable quantity of alpha hANP is $1 \mathrm{pg} /$ tube. The intra- and interassay variations were 7.2 and $7.8 \%$, respectively.

Statistical analysis. Data were expressed as mean \pm SD. Data not normally distributed were compared by the Wilcoxon's signed rank test or nonpaired rank sum test (24). Normally distributed data were compared with the paired or nonpaired $t$ test. $P<0.05$ was considered statistically significant.

\section{Results}

Catheterization data. Table I shows the cardiac catheterization data on the patients with DCM and control subjects. Cardiac index and ejection fraction were significantly reduced and pulmonary capillary wedge pressure and left ventricular end-systolic volume index were significantly increased in the patients with DCM as compared with the control subjects. Fig. 1 shows a representative coronary venogram in the left anterior oblique projection and the position of the catheter tip for sampling blood from the AIV.
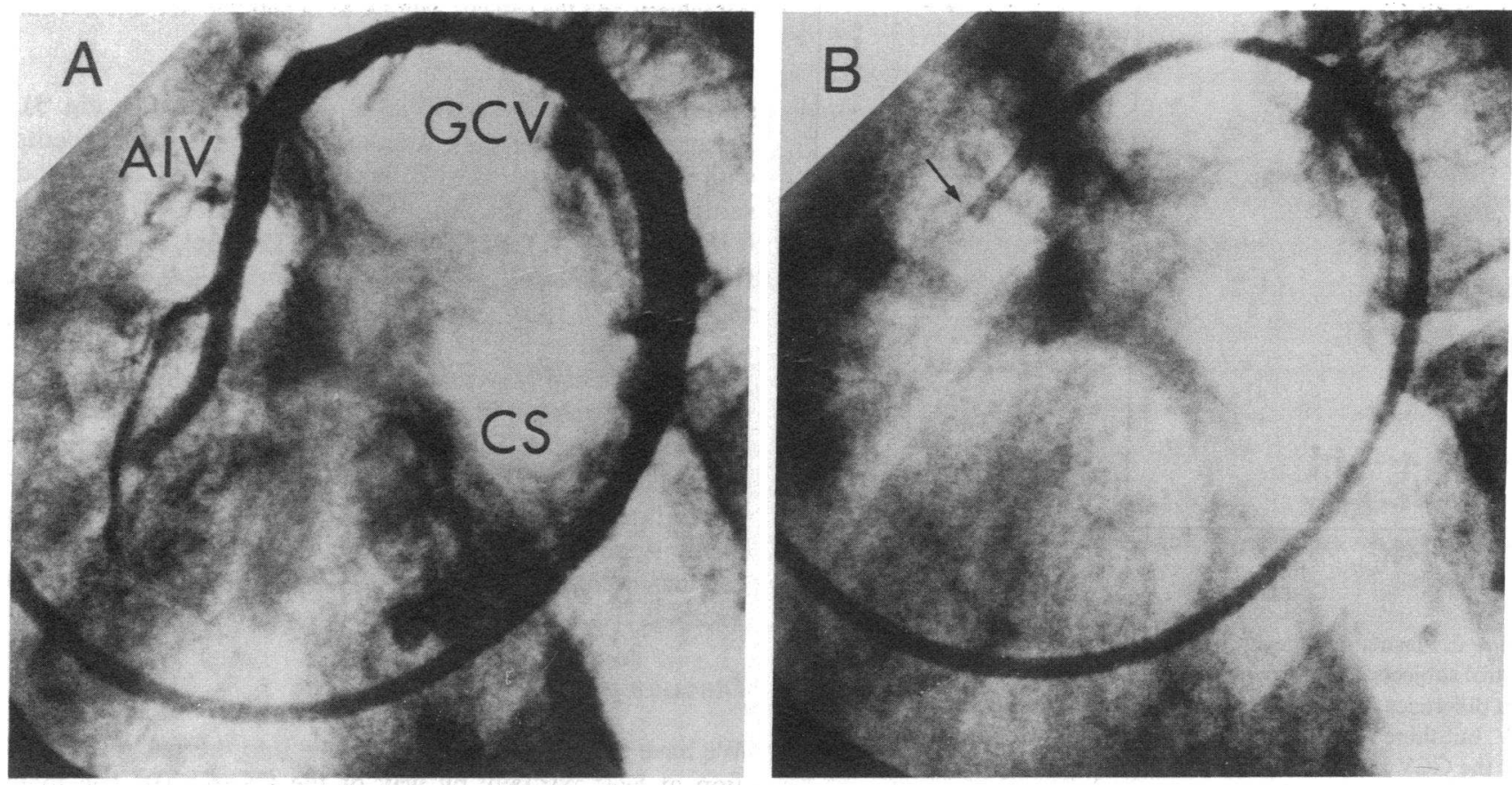

Figure 1. A representative coronary venogram in the left anterior oblique projection $(A)$ and the position of the catheter tip $(B)$. The catheter is inserted into the AIV by way of the CS and the GCV. 
Plasma ANP levels. Fig. 2 shows plasma ANP levels in the Ao, the AIV, the GCV, and the CS in the control subjects and in the patients with DCM. In the control subjects there was no significant difference in the plasma ANP levels between the Ao and the AIV (108 \pm 42 vs. $127 \pm 55 \mathrm{pg} / \mathrm{ml})$. On the contrary, there was a marked step-up in the plasma ANP levels between the AIV and the GCV $(127 \pm 55$ vs. $461 \pm 224 \mathrm{pg} / \mathrm{ml}, P$ $<0.001)$. There was also a significant step-up in the plasma ANP levels between the GCV and the CS $(461 \pm 224$ vs. $682 \pm 341 \mathrm{pg} / \mathrm{ml}, P<0.001)$. In patients with $\mathrm{DCM}$, on the other hand, there was a significant step-up in the plasma ANP levels between the Ao and the AIV (454 \pm 360 vs. $915 \pm 584$ $\mathrm{pg} / \mathrm{ml}, P<0.001)$. There was also a significant step-up in plasma ANP levels between the AIV and the GCV (915 \pm 584 vs. $1,308 \pm 926 \mathrm{pg} / \mathrm{ml}, P<0.001)$ and between the GCV and the $\mathrm{CS}(1,308 \pm 926$ vs. $1,884 \pm 1,194 \mathrm{pg} / \mathrm{ml}, P<0.001)$. Thus, the difference in plasma ANP levels between the Ao and the AIV was significantly increased in patients with DCM as compared with the control subjects $(461 \pm 248$ vs. $19 \pm 59 \mathrm{pg} / \mathrm{ml}, P$ $<0.001)$ as shown in Fig. 3. The difference in plasma ANP levels between the CS and the Ao was also significantly increased in patients with DCM as compared with the control

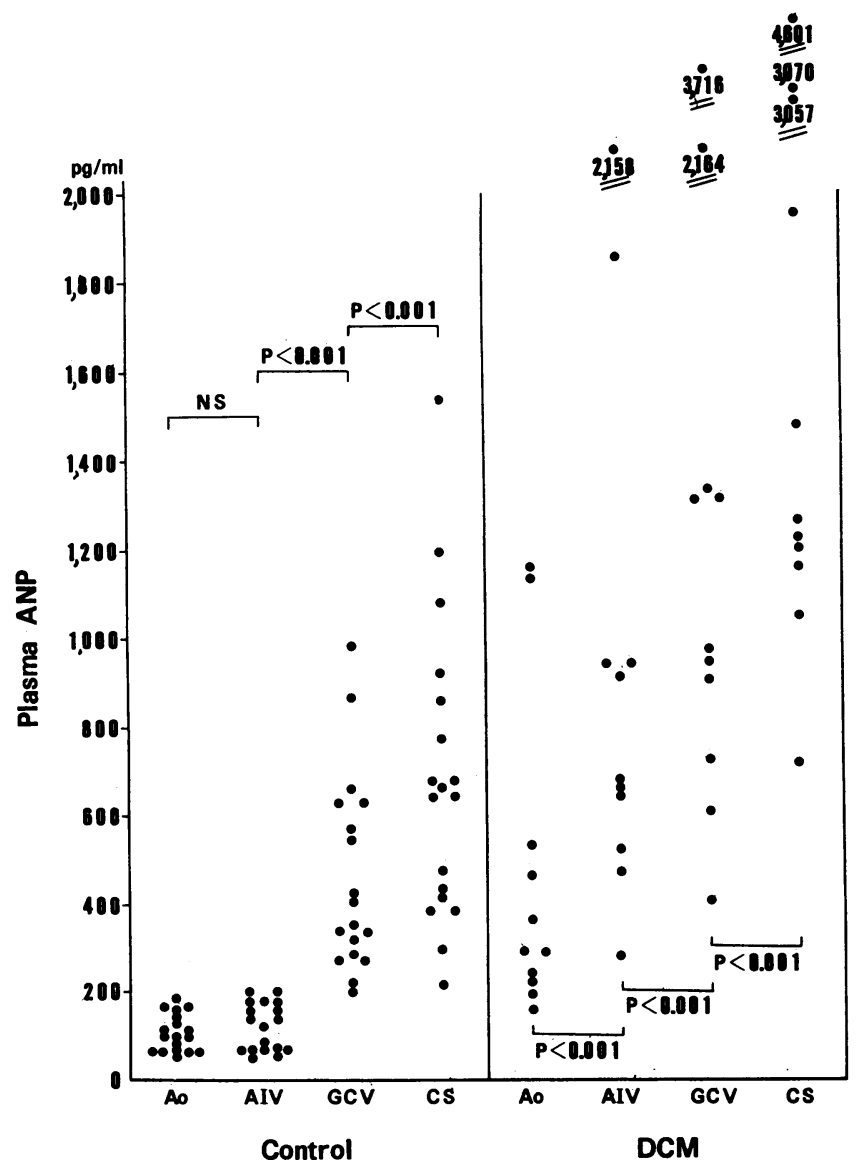

Figure 2. Plasma ANP levels in the Ao, AIV, GCV, and CS in the control subjects and the patients with DCM. There was no significant difference in the plasma ANP levels between the Ao and the AIV, but there were highly significant differences between the AIV and the GCV and between the GCV and the CS in the control subjects. On the other hand, there was a significant step-up in the plasma ANP levels between the Ao and the AIV in the patients with DCM.

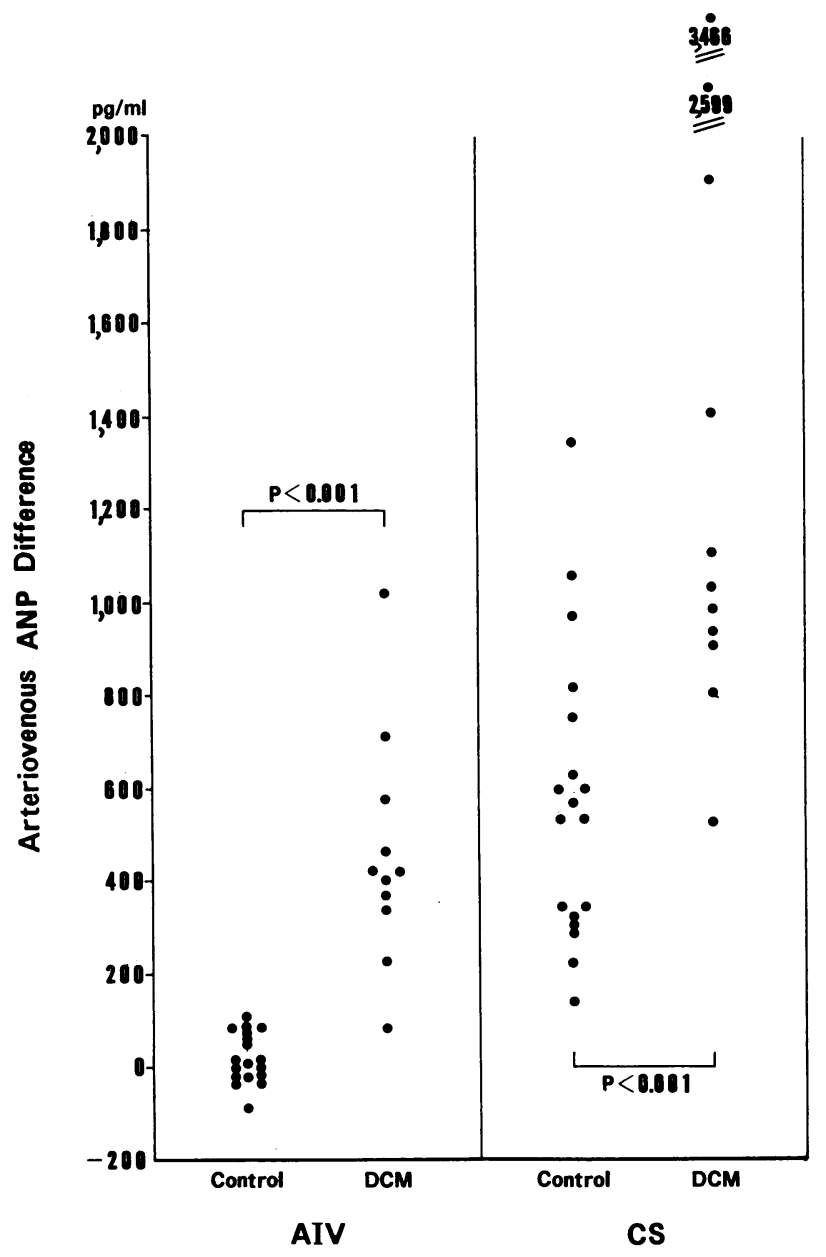

Figure 3. Arteriovenous ANP difference in the AIV and the CS in control subjects and patients with DCM. There was a highly significant difference in the arteriovenous ANP difference between the control subjects and the patients with DCM in both the AIV and the CS.

subjects $(1,429 \pm 890$ vs. $577 \pm 318 \mathrm{pg} / \mathrm{ml}, P<0.001$; Fig. 3$)$. Plasma ANP levels were significantly increased in patients with DCM as compared with the control subjects at each blood sampling site (in the Ao, $454 \pm 360$ vs. $108 \pm 42 \mathrm{pg} / \mathrm{ml}, P$ $<0.001$; in the AIV, $915 \pm 584$ vs. $127 \pm 55 \mathrm{pg} / \mathrm{ml}, P<0.001$; in the GCV $, 1,308 \pm 926$ vs. $461 \pm 224 \mathrm{pg} / \mathrm{ml}, P<0.001$; and in the CS, $1,884 \pm 1,194$ vs. $682 \pm 341 \mathrm{pg} / \mathrm{ml}, P<0.001$ ).

The difference in plasma ANP levels between the AIV and the Ao had a highly significant positive linear correlation with end-systolic volume index $(r=0.8334, P<0.001)$, a highly significant negative linear correlation with ejection fraction $(r$ $=-0.8262, P<0.001$ ), a highly significant negative linear correlation with cardiac index $(r=-0.7210, P<0.001)$, and a highly significant positive linear correlation with pulmonary capillary wedge pressure $(r=0.7176, P<0.001)$ as shown in Figs. 4 and 5.

\section{Discussion}

We have shown that ANP is released into the general circulation at least partially by way of the CS $(6,20)$. The main tributaries of CS are the GCV, the oblique vein of Marshall, the posterior vein of the left ventricle, the posterior interven- 

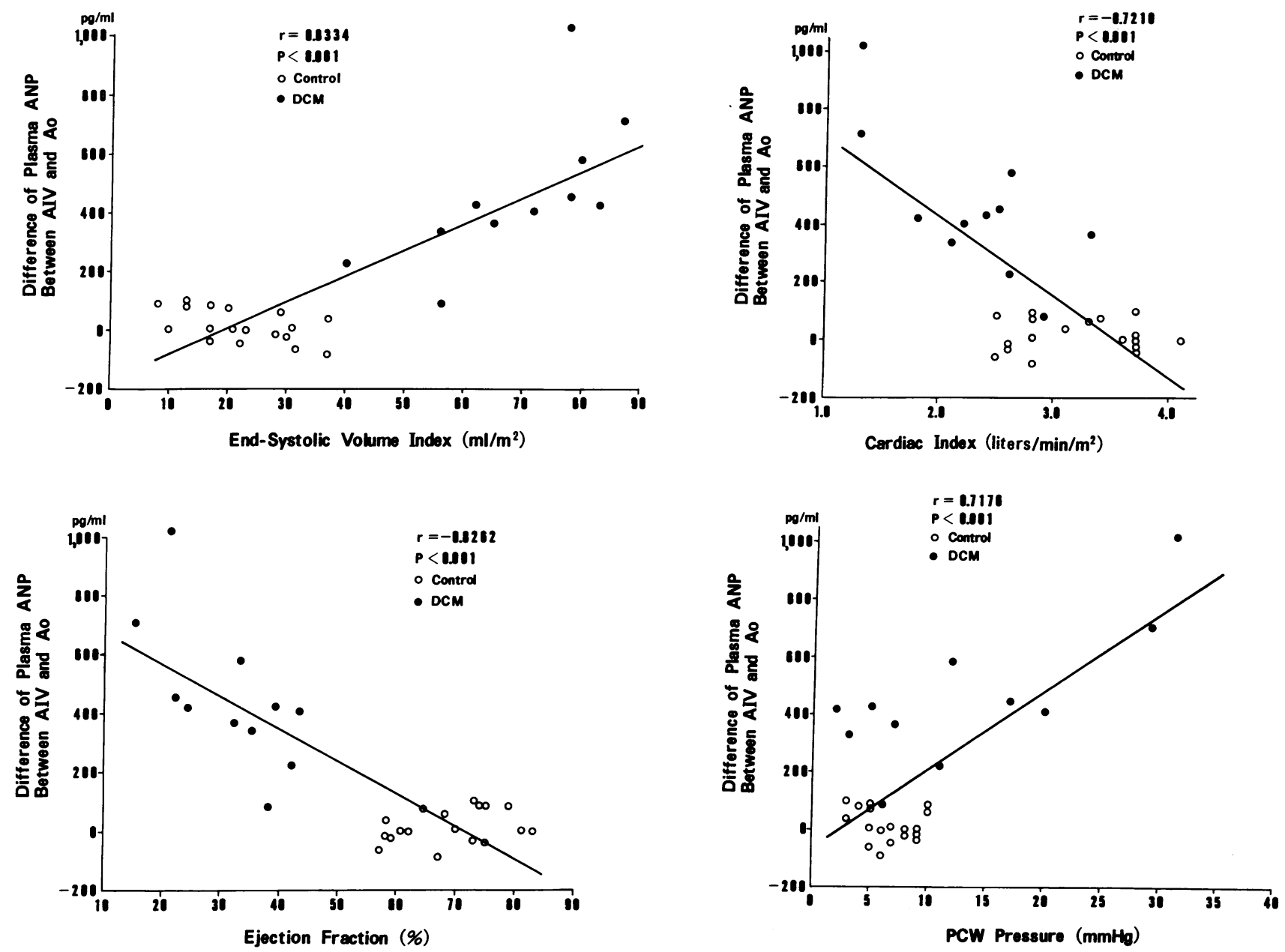

Figure 4. The difference in plasma ANP levels between AIV and Ao had a highly significant positive correlation with the end-systolic volume index (top) and a highly significant negative correlation with the ejection fraction (bottom), respectively.

tricular vein, and the small cardiac vein (21-23). Although the exact distribution and location of the venous system that drains the atria are not known, the oblique vein of Marshall and the small cardiac vein are thought to drain the left and right atrium, respectively (23). The left posterior atrial veins also drain the left atrium and empty into the CS. Thus, the GCV which is upstream to these veins is thought to contain a lower proportion of blood from the atria than the CS, and the AIV which is located in the anterior interventricular groove and is upstream to the GCV is thought to drain the left ventricle but not the atria.

In the present study blood sampling for ANP was done in the Ao, the AIV, the GCV, and the CS simultaneously. In the control subjects there was no significant difference in plasma ANP levels between the Ao and the AIV, but there were highly significant step-ups in plasma ANP levels between the AIV and the GCV and between the GCV and the CS. This indicates that ANP is not released significantly from the left ventricle in the control subjects and is increasingly released into the CS system as blood flows downstream from the AIV to the CS. In contrast, there was a highly significant step-up in the plasma ANP levels between the AIV and the Ao in patients with

Figure 5. The difference in plasma ANP levels between AIV and Ao had a significant negative correlation with cardiac index (top) and a highly positive correlation with pulmonary capillary wedge (PCW) pressure (bottom), respectively.

DCM. Thus, the present study indicates that increased amounts of ANP are released from the left ventricle into the circulation in patients with DCM. The fact that the magnitude of step-up in plasma ANP between the Ao and the AIV correlated significantly with the left ventricular end-systolic volume index, ejection fraction, and cardiac index also supports the above concept.

The present study also shows that the difference in plasma ANP levels between the CS and the Ao was significantly increased in patients with DCM as compared with the control subjects, indicating that the amount of ANP released from the heart as a whole was significantly increased in patients with DCM as compared with the control subjects.

Thus, ANP is released in increased amounts from the left ventricle as well as from the heart as a whole into the circulation in patients with DCM as compared with the control subjects. Since the pioneering work of de Bold and his co-workers (11) ANP has been thought to be secreted from the atria and not from the ventricles in adult mammals $(1-5,12)$. However, several recent reports indicate that ANP is also synthesized in small amounts in the extra-atrial sites, including the ventricles $(14,25-28)$, and in substantial amounts in ventricles with hy- 
pertrophy or heart failure (13-17) in animals. Recently, Edwards and his co-workers demonstrated immunohistochemically the presence of immunoreactive ANP in the ventricles of autopsied and biopsied humans with heart failure, but not in the control autopsied human hearts (19). We also have reported an autopsy case of DCM in which tissue levels of ANP and ANP mRNA were markedly increased in the left ventricle as compared with those in the control subjects (18). The present study confirms and extends our own previous study and that of Edwards and his co-workers, and demonstrates that an increased amount of ANP is actually released from the left ventricle into the circulation and contributes significantly to the elevation of plasma ANP levels in patients with DCM.

The mechanism(s) by which increased secretion of ANP occurs from the left ventricle in patients with DCM is unclear at the present time. Increased wall tension or stretch as a consequence of volume overload may stimulate the secretion of ANP from the left ventricle as from the atria (29). The demonstration in this study that the magnitude of step-up in the plasma ANP levels between the Ao and the AIV had a highly significant positive linear correlation with the left ventricular end-systolic volume index supports this interpretation. We (30) and other workers $(8,31)$ have shown that infusion of ANP in patients with congestive heart failure, including those with DCM, improves left ventricular function by reducing both the increased preload and afterload. Thus, increased secretion of ANP from the left ventricle in patients with DCM may represent an important compensatory mechanism for heart failure.

Previous studies have demonstrated that ANP is synthesized in substantial amounts in the ventricles of fetal rats (25-28) and human fetuses (32); thus the increased release of ANP from the left ventricle in patients with DCM may indicate the presence of cardiomyocytes of a fetal type in the ventricles of patients with DCM as suggested by recent studies $(33,34)$.

\section{References}

1. de Bold, A. J. 1985. Atrial natriuretic factor: a hormone produced by the heart. Science (Wash. DC). 230:767-770.

2. Laragh, J. H. 1985. Atrial natriuretic hormone, the renin-aldosterone axis, and blood pressure-electrolyte homeostasis. N. Engl. J. Med. 313:1330-1340.

3. Needleman, P., and J. E. Greenwald. 1986. Atriopeptin: a cardiac hormone intimately involved in fluid, electrolyte, and bloodpressure homeostasis. N. Engl. J. Med. 314:828-834.

4. Ballermann, B. J., and B. M. Brenner. 1986. Role of atrial peptides in body fluid homeostasis. Circ. Res. 58:619-630.

5. Genest, J., and M. Cantin. 1987. Atrial natriuretic factor. Circulation. 75(Suppl. I): 118-124.

6. Sugawara, A., K. Nakao, N. Morii, M. Sakamoto, M. Suda, M. Shimokura, Y. Kiso, M. Kihara, Y. Yamori, K. Nishimura, et al. 1985. Alpha-human atrial natriuretic polypeptide is released from the heart and circulates in the body. Biochem. Biophys. Res. Commun. 129:439-446.

7. Burnett, J. C., Jr., P. C. Kao, D. C. Hu, D. W. Heser, D. Heublein, J. P. Granger, T. J. Opgenorth, and G. S. Reeder. 1986. Atrial natriuretic peptide elevation in congestive heart failure in the human. Science (Wash. DC). 231:1145-1147.

8. Cody, R. J., S. A. Atlas, J. H. Laragh, S. H. Kubo, A. B. Covit, K. S. Ryman, A. Shaknovich, K. Pondolfino, M. Clark, M. J. J. Ca- margo, and R. M. Scarborough. 1986. Atrial natriuretic factor in normal subjects and heart failure patients. J. Clin. Invest. 78:1362-1374.

9. Rodeheffer, R. J., I. Tanaka, T. Imada, A. S. Hollister, D. Robertson, and T. Inagami. 1986. Atrial pressure and secretion of atrial natriuretic factor into the human central circulation. J. Am. Coll. Cardiol. 8:18-26.

10. Raine, A. E. G., D. Phil, P. Erne, E. Burgisser, F. B. Muller, P. Bolli, F. Burkart, and F. R. Buhler. 1986. Atrial natriuretic peptide and atrial pressure in patients with congestive heart failure. N. Engl. J. Med. 315:533-537.

11. de Bold, A. J., H. B. Borenstein, A. T. Veress, and H. Sonnenberg. 1981. A rapid and potent natriuretic response to intravenous injection of atrial myocardial extract in rats. Life Sci. 28:89-94.

12. Kangawa, K., and H. Matsuo. 1984. Purification and complete amino acid sequence of alpha-human atrial natriuretic polypeptide. Biochem. Biophys. Res. Commun. 118:131-139.

13. Lattion, A. L., J. B. Michel, E. Arnauld, P. Corvol, and F. Soubrier. 1986. Myocardial recruitment during ANF mRNA increase with volume overload in the rat. Am. J. Physiol. 251:H890-H896.

14. Day, M. L., D. Schwartz, R. C. Wiegand, P. T. Stockman, S. R. Brunnert, H. E. Tolunay, M. G. Currie, D. G. Standaert, and P. Needleman. 1987. Ventricular atriopeptin:unmasking of messenger RNA and peptide synthesis by hypertrophy or dexamethasone. Hypertension (Dallas). 9:485-491.

15. Ding, J., G. Thibault, J. Gutkowska, R. Garcia, T. Karabatsos, G. Jasmin, J. Genest, and M. Cantin. 1987. Cardiac and plasma atrial natriuretic factor in experimental congestive heart failure. Endocrinology. 121:248-257.

16. Franch, H. A., R. A. Dixon, E. H. Blaine, and P. K. Siegl. 1988. Ventricular atrial natriuretic factor in the cardiomyopathic hamster model of congestive heart failure. Circ. Res. 62:31-36.

17. Arai, H., K. Nakao, Y. Saito, N. Morii, A. Sugawara, T. Yamada, H. Itoh, S. Shiono, M. Mukoyama, H. Ohkubo, et al. 1987. Simultaneous measurement of atrial natriuretic polypeptide (ANP) messenger RNA and ANP in rat heart. Evidence for a preferentially increased synthesis and secretion of ANP in left atrium of spontaneously hypertensive rats (SHR). Biochem. Biophys. Res. Commun. 148:239-244.

18. Saito, Y., K. Nakao, H. Arai, A. Sugawara, N. Morii, T. Yamada, H. Itoh, S. Shiono, M. Mukoyama, K. Obata, et al. 1987. Atrial natriuretic polypeptide (ANP) in human ventricle: increased gene expression of ANP in dilated cardiomyopathy. Biochem. Biophys. Res. Commun. 148:211-217.

19. Edwards, B. S., D. M. Ackermann, M. E. Lee, G. S. Reeder, L. E. Wold, and J. C. Burnett, Jr. 1988. Identification of atrial natriuretic factor within ventricular tissue in hamsters and humans with congestive heart failure. J. Clin. Invest. 81:82-86.

20. Obata, K., H. Yasue, Y. Horio, S. Naomi, T. Umeda, T. Sato, A. Miyata, and H. Matsuo. 1987. Increase of human atrial natriuretic polypeptide in response to cardiac pacing. Am. Heart J. 113:845-847.

21. Gensini, G. G., S. D. Giorgi, O. Coskun, and A. Palacio. 1965. Anatomy of the coronary circulation in living man: coronary venography. Circulation. 31:778-784.

22. Roberts, D. L., H. K. Nakazawa, and F. J. Klocke. 1976. Origin of great cardiac vein and coronary sinus drainage within the left ventricle. Am. J. Physiol. 230:486-492.

23. Tschabitscher, M. 1984. Anatomy of coronary veins. In The Coronary Sinus. W. Mohl, E. Wolner, and D. Glogar, editors. Springer-Verlag New York, Inc., New York, 8-25.

24. Snedecor, G. W., and W. G. Cochran. 1980. Statistical Methods. The Iowa State University Press, Ames, IA. 135 pp.

25. Bloch, K. D., J. G. Seidman, J. D. Naftilan, J. T. Fallon, and C. E. Seidman. 1986. Neonatal atria and ventricles secrete atrial natriuretic factor via tissue-specific secretory pathways. Cell. 47:695-702.

26. Gardner, D. G., C. F. Deschepper, W. F. Ganong, S. Hane, J. Fiddes, J. D. Baxter, and J. Lewicki. 1986. Extra-atrial expression of the gene for atrial natriuretic factor. Proc. Natl. Acad. Sci. USA. 83:6697-6701. 
27. Nemer, M., J. P. Lavigne, J. Drouin, G. Thibault, M. Gannon, and T. Antakly. 1986. Expression of atrial natriuretic factor gene in heart ventricular tissue. Peptides (NY). 7:1147-1152.

28. Wei, Y., C. P. Rodi, M. L. Day, R. C. Wiegand, L. D. Needleman, B. R. Cole, and P. Needleman. 1987. Developmental changes in the rat atriopeptin hormonal system. J. Clin. Invest. 79:1325-1329.

29. Edwards, B. S., R. S. Zimmerman, T. R. Schwab, D. M. Heublin, and J. C. Burnett, Jr. 1988. Atrial stretch, not pressure, is the principal determinant controlling the acute release of atrial natriuretic factor. Circ. Res. 62:191-195.

30. Saito, Y., K. Nakao, K. Nishimura, A. Sugawara, K. Okumura, K. Obata, R. Sonoda, T. Ban, H. Yasue, and H. Imura. 1987. Clinical application of atrial natriuretic polypeptide in patients with congestive heart failure: beneficial effects on left ventricular function. Circulation. 76:115-124.
31. Crozier, I. G., M. G. Nicholls, H. Ikram, E. A. Espiner, H. J. Gomez, and N. J. Warner. 1986. Hemodynamic effects of atrial peptide infusion in heart failure. Lancet. ii:1242-1245.

32. Kikuchi, K., K. Nakao, K. Hayashi, N. Morii, A. Sugawara, M. Sakamoto, H. Imura, and H. Mikawa. 1987. Ontogeny of atrial natriuretic polypeptide in human heart. Acta Endocrinol. 115:211-216.

33. Hirzel, H. O., C. R. Tuchschmid, J. Schneider, H. P. Krayenbuehl, and M. C. Schaub. 1985. Relationship between myosin isoenzyme composition, hemodynamics, and myocardial structure in various forms of human cardiac hypertrophy. Circ. Res. 57:729-740.

34. Tsuchimochi, H., Y. Yazaki, M. Kawana, S. Kimata, and F. Takaku. 1987. The existence of a fetal type myosin heavy chain (MHC) in the human heart and its abnormal expression in the ventricles of dilated cardiomyopathy. Circulation. 76(Suppl.):IV-262. (Abstr.) 